\title{
Design da informação em bulas de medicamento: análise e classificação da estrutura e apresentação gráfica de seu conteúdo textual
}

\author{
Information design on medicine inserts: analysis and classification of the structure and \\ graphic presentation of its textual content
}

bula de medicamento, estrutura textual, apresentação gráfica

\begin{abstract}
Este artigo aborda a bula de medicamento na perspectiva do design da informação. São apresentadas referências teóricas que ratificam a bula como um documento essencial no uso de medicamentos e a necessidade de sua investigação. Foram também abordados os referenciais teóricos sobre a estrutura textual da bula de medicamento em relação à apresentação gráfica de seu conteúdo. Quanto à estrutura, apresentam-se as funções textuais da bula denominadas por Marshall (1984) e sua classificação superestrutural, de acordo com Van Dijk (1992). Sobre a apresentação gráfica, são apresentados e analisados os aspectos gráficos e deficiências de ordem gráfico-informacional do conteúdo que dificultam a leitura e compreensão das bulas de medicamentos.
\end{abstract}

medicine insert, textual structure, graphic presentation

This paper approaches the medicine insert on the perspective of information design. Some theoretical references are presented, in order to justify the medicine insert as an essential document in the use of medicines and the need of its investigation. Moreover, aspects about the medicine insert's textual structure and graphic presentation were discussed. In concern to the textual structure, are presented the textual function of the medicine insert defined by Marshall (1984) and its superstructure classification according to van Dijk (1992). The graphic presentation is discussed taking into account the graphic aspects in the communication efficacy and the graphic-informational deficiencies that make difficult its reading and comprehension.

\section{Introdução}

A bula de medicamento é um documento de consulta pública, imprescindível no uso de medicamentos, pois fornece informações específicas sobre sua composição química, precauções/advertências/cuidados (e.g. uso, acondicionamento do medicamento), formas de ministrar e até mesmo como preparar um medicamento (e.g. antibióticos em suspensão).

No Brasil, o conteúdo informacional das bulas é regulamentado pela ANVISA - Agência Nacional de Vigilância Sanitária (órgão do Ministério da Saúde). Segundo esta instituição, a bula é um documento legal sanitário direcionada a pacientes e a profissionais da saúde que contém informações técnico-científicas e orientadoras sobre medicamentos para o seu uso racional. $\mathrm{Na}$ perspectiva de garantir a qualidade e completude do conteúdo veiculado em bulas de medicamento a ANVISA estabelece regras em ementa não oficial (Resolução RDC No 140, 2003), que em síntese consistem em: identificação do medicamento, formas farmacêuticas, advertências, informações técnicas aos profissionais da saúde, informações ao paciente e dizeres legais.

Apesar da preocupação com a qualidade e tipo de conteúdo informacional veiculado em bulas de medicamentos, a legislação apresenta apenas uma recomendação em relação à apresentação gráfica do conteúdo textual: fonte (letra) de tamanho mínimo de 1,55mm (SPINILLO et al, 2007). Aspectos como legibilidade, clareza nas instruções visuais (quando empregadas) e qualidade na apresentação gráfica do conteúdo textual e estrutura do documento são desconsiderados, apesar da relevância destes aspectos na leitura e compreensão de uma mensagem impressa (e.g. WRIGHT,1999; SLESS \& TYERS, 2004; VAN DER WAARDE, 2004, 2006). Além destes aspectos encontram-se diferentes tipos de informação contidos na bula, como advertências, tabelas, diagramas e termos específicos da área de saúde, que as tornam um documento de considerável 


\section{Infodesıgn}

complexidade lingüística e gráfica para os pacientes/usuários com pouca ou nenhuma experiência de leitura sobre este tipo de conteúdo.

A apresentação gráfica do conteúdo informacional nas bulas de medicamento influencia sua leitura e compreensão, e, portanto o uso dos medicamentos. Deficiências tanto ao nível de conteúdo quanto na apresentação gráfica das informações em bulas podem levar ao mau uso de medicamentos, comprometendo o bem-estar e até acarretando sérias conseqüências na saúde do paciente/usuário (FUJITA \& SPINILLO, 2006).

A bula de medicamento contém informações que são de interesse a dois tipos de usuários: profissionais da saúde e pacientes. Porém, as necessidades informacionais dos pacientes/usuários podem diferir dos profissionais da saúde/usuários. Segundo Dickinson e Raynor (2003) os pacientes geralmente priorizam informações sobre um fármaco relacionadas aos efeitos colaterais, contra-indicações, e posologia (modo de uso), enquanto que aos profissionais da saúde interessam as informações técnicas, farmacológicas e de composição do medicamento.

O não suprimento das necessidades informacionais e a falta de experiência do leitor com a informação podem levar à incompreensão de seu conteúdo e, portanto, influenciar negativamente o desempenho na execução de tarefas relacionadas a um produto (e.g. tomar um medicamento ou trocar o pneu de um carro). Dependendo do tipo de documento, põe-se em risco a vida do usuário, como é o caso de informações na área de saúde direcionadas à pacientes/usuários.

Considerando a importância das informações contidas na bula para o uso de medicamentos, este artigo aborda a relação entre a estrutura e a apresentação gráfica de seu conteúdo informacional.

\section{A estrutura informacional da bula de medicamento}

Segundo Giasson (1993), o texto é o material preparado para ser lido, podendo ser considerado sob três aspectos: a intenção do autor, a estrutura do texto e o conteúdo. O autor estrutura o texto direcionando-o a um tipo de leitor, e orientando-o aos outros dois elementos (texto e conteúdo). A estrutura diz respeito à forma como o autor organizou as idéias no texto, e o conteúdo se refere ao modo como o autor decidiu transmiti-las, tais como, conceitos, conhecimentos e vocabulário. Nesta perspectiva, Marshall (1984) apud Giasson (1993), propõe um modo de classificar textos, no que diz respeito à sua estrutura (Quadro 1):

Quadro 1: Modelo de classificação textual (Fonte: MARSHALL, 1984)

\begin{tabular}{|l|l|l|}
\hline Funções (intenção do autor) & Forma \\
\cline { 2 - 3 } & Seqüência Temporal & Tema \\
\hline Agir sobre as emoções & $\begin{array}{l}\text { Texto narrativo (conto, narrativa, lenda, } \\
\text { romance...) }\end{array}$ & $\begin{array}{l}\text { Texto poético } \\
\text { (expressivo) }\end{array}$ \\
\hline Agir sobre o comportamento & $\begin{array}{l}\text { Texto diretivo (receitas, regras de jogo, } \\
\text { instruções...) }\end{array}$ & $\begin{array}{l}\text { Texto incitativo } \\
\text { (persuasivos) }\end{array}$ \\
\hline Agir sobre os conhecimentos & $\begin{array}{l}\text { Texto informativo (com seqüência } \\
\text { temporal: acontecimentos históricos) }\end{array}$ & $\begin{array}{l}\text { Texto informativo } \\
\text { (conhecimento) }\end{array}$ \\
\hline
\end{tabular}

De acordo com a tabela 2, Marshall (1984), relaciona a existência de seqüência temporal (que tem a ver com a estrutura do texto) às intenções de comunicação do autor (funções), que determinam o seu tema.

Tendo isso em vista, é possível relacionar este modelo à estrutura da bula de medicamento: o texto se refere ao conteúdo da bula, cujo autor é o fabricante do medicamento que estrutura o texto da bula, com a função de agir sobre o comportamento e conhecimento do leitor (paciente), classificando-se como um texto diretivo informativo.

Com relação a esta descrição, Walker (2001) considera que o autor através da estrutura utilizada no texto, determina as características da mensagem escrita, tanto na linguagem utilizada como na forma de organização visual (e.g. carta formal impressa ou informal escrita à mão); e ainda afirma que existe uma relação natural entre a organização visual de um documento e a sua intenção de uso, por isso é preciso considerar quem irá utilizá-lo e como será utilizado no processo de design de conteúdos textuais que, no caso da bula, é o leitor/paciente. 
Para Van Dijk (1992), o que o leitor procura durante a leitura é a informação importante, podendo esta variar de um leitor para outro. Em vista disso, são consideradas duas categorias de informação importantes: a informação textualmente importante considerada pelo autor; e a informação contextualmente importante considerada pelo leitor mediante a sua intenção de leitura.

No caso da informação contextualmente importante considerada pelo leitor, identificam-se no conteúdo da bula, informações direcionadas a diferentes tipos de leitor: [a] informações de interesse de médicos e profissionais da saúde, que se referem à composição, características químicas e farmacológicas do medicamento; e [b] informações para o interesse do paciente direcionado, talvez, nos efeitos colaterais, posologia, advertências e indicações terapêuticas, redigido em um texto de um único documento que, em principio, deve ser entendido por todos os tipos de leitores. Desta forma, pode se inferir que a natureza da bula de medicamento é desse modo, a de um documento informativo dirigido a todos envolvidos em seu uso, e não de um conteúdo informacional direcionado às necessidades informacionais do paciente como usuário final.

Quanto à informação considerada pelo autor na bula, apesar de ser composta pelos fabricantes de medicamentos com todas as informações exigidas pela legislação da ANVISA, parece não se vincular a uma preocupação de como será lida e compreendida, tanto com relação à linguagem e estrutura textual utilizada como à sua apresentação gráfica.

\subsection{Classificação e análise da estrutura textual da bula de medicamento}

A estrutura de um texto está diretamente conectada ao seu conteúdo, podendo, portanto variar com diferentes tipos e níveis. Neste sentido, Van Dijk (1992) denomina as diferentes estruturas globais como superestruturas que caracterizam os tipos de texto. A superestrutura, segundo Van Dijk (1992), é a forma de um texto e sua macroestrutura, o conteúdo. O autor ressalta que os tipos de textos se distinguem entre si, não só por suas diferentes funções comunicativas, mas também por suas funções sociais, sendo que possuem tipos de construção distintos.

Para Ferreira e Dias (2005), a leitura de um texto além de ser determinada pelos conhecimentos e experiências do leitor, é também definida por sua superestrutura. Nesta perspectiva a superestrutura exige diferentes tipos de estratégias e determina a natureza da relação que o leitor mantém com o texto. Desta forma, a autora valida que a posição de um leitor frente a um texto muda de acordo com a sua superestrutura (e.g. uma lista telefônica não é de natureza similar a que ele assume frente a um texto narrativo, por exemplo), de modo que a superestrutura textual orienta a leitura que o leitor faz do texto (FERREIRA \& DIAS, 2005).

As superestruturas podem ser representadas por três tipos de estruturas textuais: narrativa, argumentativa e institucional. Segundo Van Dijk (1992) a narrativa é a estrutura mais básica, pois se caracteriza pela comunicação cotidiana (e.g. contamos a alguém o que fizemos durante o dia ou uma viagem), sendo que as descrições das circunstâncias e objetos ou fatos são subordinados às ações dos sujeitos da narração contados por apenas um narrador (desta forma se diferencia um texto narrativo de um catálogo, por exemplo). A estrutura argumentativa se baseia na seqüência hipótese-conclusão, e atua com um diálogo persuasivo (e.g. artigo científico ou anúncio publicitário).

De acordo com Van Dijk (1992) existem estruturas textuais que não são convencionais (narrativas e/ou argumentativas), mas institucionais porque se baseiam em regras/normas de uma determinada instituição social. A bula de medicamento é dotada de uma estrutura institucional, pois seu conteúdo é estruturado por normas estabelecidas pela ANVISA. O Quadro 2 a seguir apresenta em ordem sequencial a estrutura do conteúdo da bula de medicamento de acordo com as normas estabelecidas pela ANVISA (Resolução RDC No 140, 2003). 


\section{Infodesıgn}

Quadro 2: Estrutura textual da bula de medicamento, de acordo com as normas da ANVISA (Resolução RDC No 140, 2003).

\begin{tabular}{|c|c|}
\hline Títulos & Subtítulos \\
\hline \multirow[t]{3}{*}{ [1[ Identificação do medicamento } & Nome comercial ou marca do medicamento. \\
\hline & $\begin{array}{l}\text { Formas farmacêuticas, vias de administração e } \\
\text { apresentações comercializadas. }\end{array}$ \\
\hline & $\begin{array}{l}\text { Composição: Peso, volume líquido ou quantidade de } \\
\text { unidades, conforme o caso. }\end{array}$ \\
\hline \multirow{8}{*}{ [2[ Informações ao paciente } & Ação do medicamento. \\
\hline & Indicações do medicamento \\
\hline & $\begin{array}{l}\text { Riscos do medicamento (contra-indicações, advertências, } \\
\text { precauções e principais interações medicamentosas, } \\
\text { inclusive com alimentos e testes laboratoriais) }\end{array}$ \\
\hline & Modo de uso ou posologia \\
\hline & Reações adversas \\
\hline & Conduta em caso de superdose \\
\hline & Cuidados de conservação e uso \\
\hline & Características farmacológicas \\
\hline \multirow{12}{*}{$\begin{array}{l}\text { [3] Informações Técnicas aos } \\
\text { profissionais da saúde }\end{array}$} & Resultados de eficácia \\
\hline & Indicações \\
\hline & Contra indicações \\
\hline & $\begin{array}{l}\text { Modo de usar e cuidados de conservação depois de } \\
\text { aberto }\end{array}$ \\
\hline & Posologia \\
\hline & Advertências \\
\hline & Uso em idosos, crianças e outros grupos de risco \\
\hline & Interações medicamentosas \\
\hline & Reações adversas a medicamentos \\
\hline & Superdose \\
\hline & Armazenagem \\
\hline & Número do registro na ANVISA/MS \\
\hline
\end{tabular}

De acordo com o Quadro 2, é possível observar que o conteúdo da bula é dividido pela ANVISA em quatro itens principais, respectivamente: [1] Identificação do medicamento, [2] Informações ao paciente, [3] Informaç̧̃̃es técnicas aos profissionais da saúde e [3] Dizeres legais. Estes itens são apresentados visualmente em uma bula na Figura 1 a seguir: 
Figura 1: Apresentação visual dos principais itens da bula.

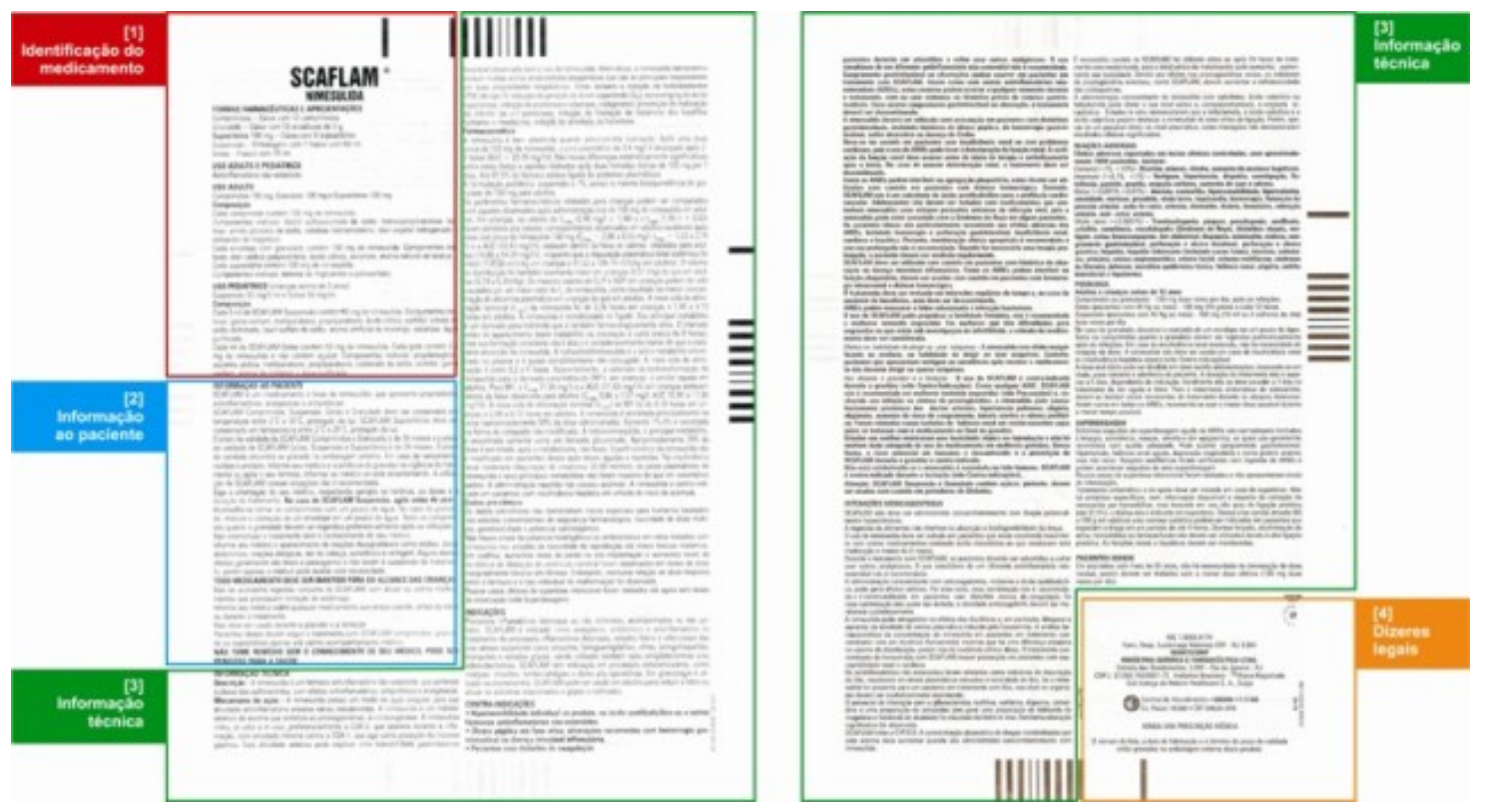

O item [1] Identificação do medicamento, apresenta informações sobre nome do medicamento, formas farmacêuticas (e.g. comprimido ou supensão) e composição química (Figura 2).

Figura 2: [1] Identificação do medicamento

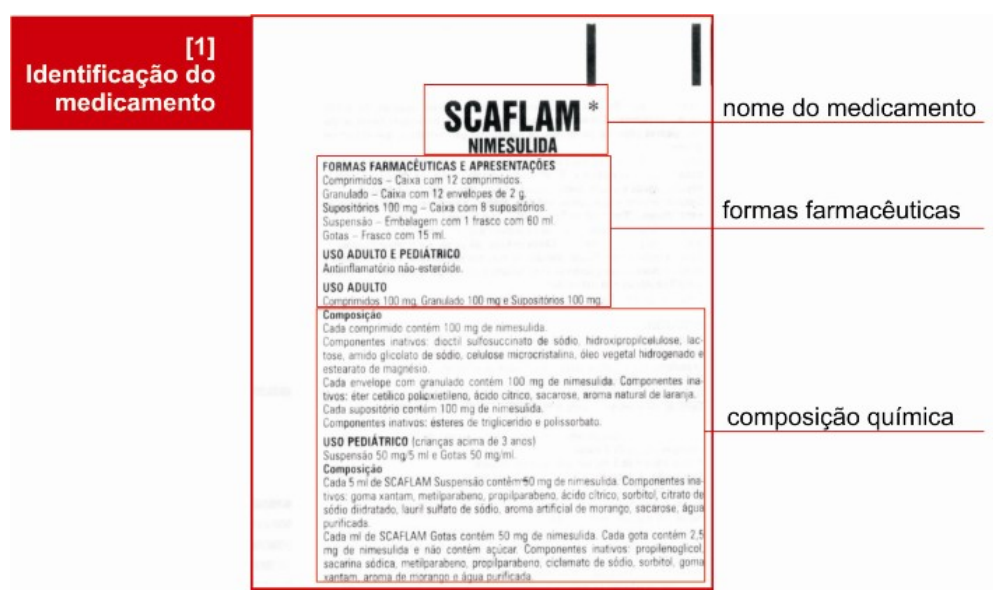

Na seqüência, o item [2] Informação ao paciente, que segundo a ANVISA é direcionado ao paciente, aborda conteúdos, tais como: ação do medicamento (como o medicamento funciona), descrição das ações farmacológicas, indicações de uso, riscos do medicamento, contraindicações, advertências, precauções e principais interações medicamentosas, modo de uso, reações adversas, conduta em caso de superdose, cuidados de conservação e uso, e características farmacológicas (Figura 3). 


\section{InfĐdesıgn}

Figura 3: Informação ao paciente

\begin{tabular}{|c|c|c|}
\hline $\begin{array}{r}\text { [2] } \\
\text { Informação } \\
\text { ao paciente }\end{array}$ & 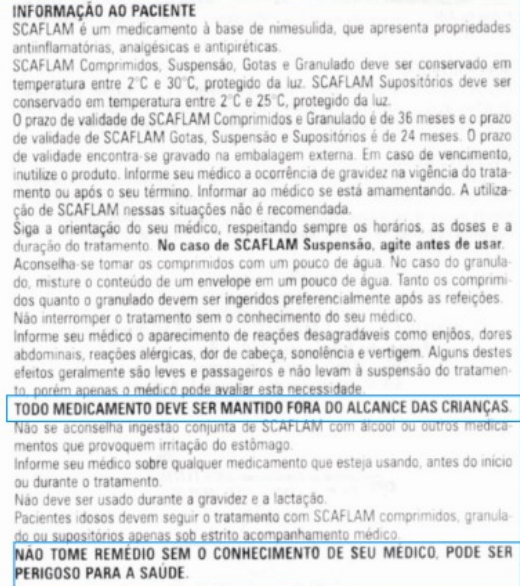 & Advertências \\
\hline
\end{tabular}

De acordo com a Resolução RDC No 140 (2003): "as informações ao paciente são obrigatórias e devem ser escritas em linguagem acessível, o texto deve ser de fácil compreensão para o paciente e pode ser na forma de perguntas e respostas". Porém, estas normas não especificam a forma como este conteúdo deve ser apresentado (e.g. se deve ser apresentado em seqüência de itens ou redigido em um único texto).

As [3] Informações técnicas (Figura 4), segundo a ANVISA são direcionadas aos profissionais da saúde. Descrevem o medicamento com as suas propriedades farmacológicas fundamentadas técnico-cientificamente, e devem obrigatoriamente abordar: resultados de eficácia, indicações terapêuticas, contra indicações, modo de usar e cuidados de conservação depois de aberto, posologia, advertências, uso em idosos, crianças e outros grupos de risco, interações medicamentosas, reações adversas a medicamentos, superdose, armazenagem.

Figura 4: Informação técnica

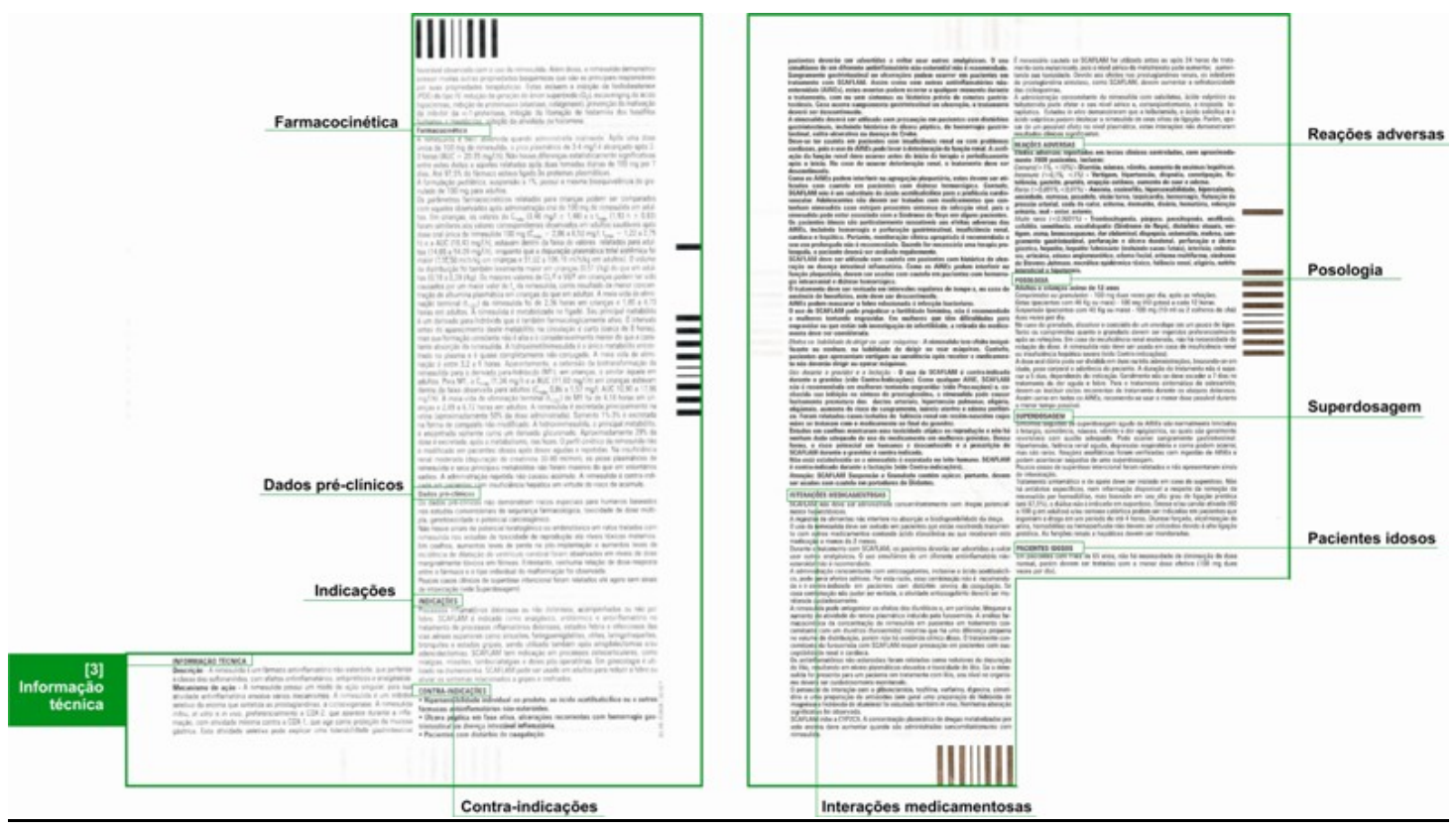

Os [4] Dizeres legais devem conter obrigatoriamente: número do registro na ANVISA/MS; nome do Farmacêutico responsável e respectivo número de inscrição no Conselho Regional de Farmácia da Unidade Federativa; nome completo e endereço do fabricante e do titular do registro; Cadastro Nacional de Pessoa Jurídica, CNPJ; Telefone do Serviço de Atendimento ao Consumidor da empresa (Figura 5). As normas também informam para incluir, se necessário, os 
dizeres: "Uso restrito a hospitais"; "Venda sob prescrição médica"; "Dispensação sob prescrição médica" (para laboratórios oficiais) e "Proibida a venda ao comércio".

Figura 5: Dizeres legais

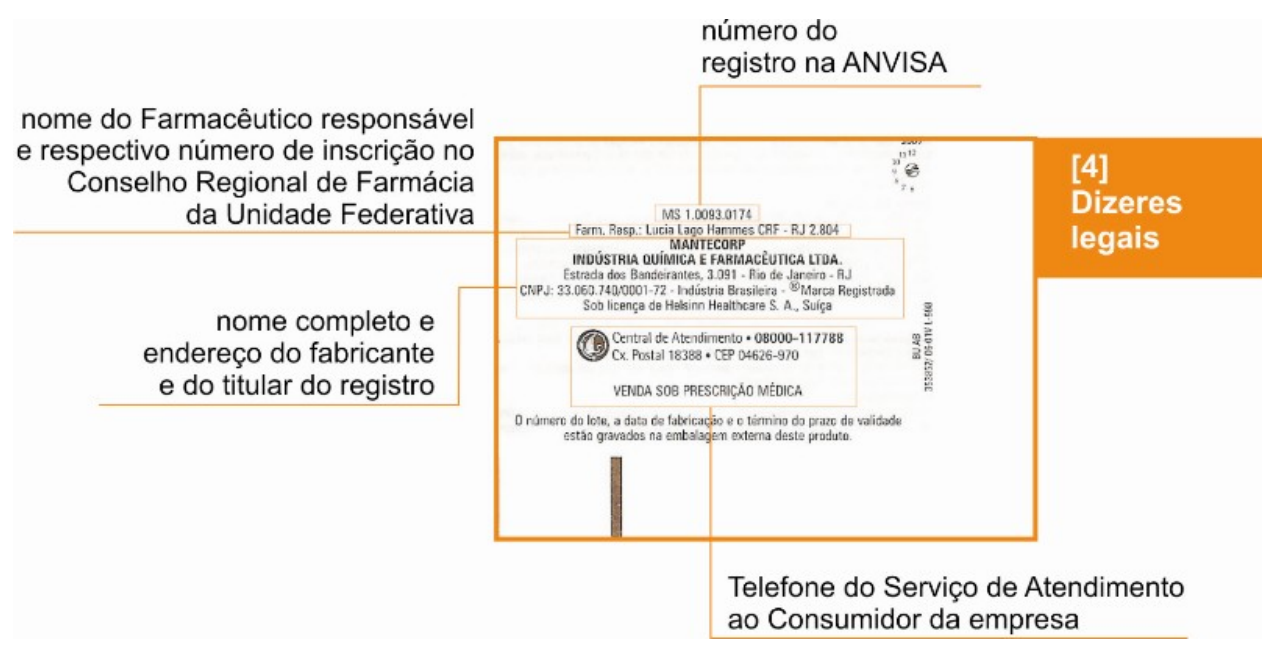

Em síntese, sobre a estrutura apresentaram-se as funções textuais da bula denominadas por Marshall (1984) e sua classificação superestrutural, de acordo com Van Dijk (1992). O Quadro 3 sintetiza esta classificação da bula de acordo com Van Dijk (1992) e Marshall (1984):

Quadro 3: Classificação textual da bula de acordo com Van Dijk (1992) e Marshall (1984)

\begin{tabular}{|l|l|l|l|l|}
\cline { 2 - 5 } \multicolumn{1}{c|}{} & \multicolumn{2}{l|}{ Marshall (1984) } & \multicolumn{2}{l|}{ Van Dijk (1992) } \\
\hline documento & $\begin{array}{l}\text { funções (intenção do } \\
\text { autor) }\end{array}$ & $\begin{array}{l}\text { sequência } \\
\text { temporal }\end{array}$ & $\begin{array}{l}\text { Superestrutura } \\
\text { (estrutura textual) }\end{array}$ & $\begin{array}{l}\text { macroestrutura } \\
\text { (conteúdo) }\end{array}$ \\
\cline { 2 - 5 } & $\begin{array}{l}\text { agir sobre o } \\
\text { comportamento e o } \\
\text { conhecimento }\end{array}$ & $\begin{array}{l}\text { Texto diretivo } \\
\text { informativo }\end{array}$ & $\begin{array}{l}\text { institucional } \\
\text { regras/normas de } \\
\text { uma determinada } \\
\text { instituição social. }\end{array}$ \\
\hline Bula & $\begin{array}{l}\text { instruir e informar sobre o uso do } \\
\text { medicamento }\end{array}$ & $\begin{array}{l}\text { Regras estabelecidas pela ANVISA } \\
\text { (Resolução RDC No 140, 2003) }\end{array}$ \\
\hline
\end{tabular}

De acordo com o modelo de Marshall (1984), o texto da bula de medicamento foi determinado como diretivo informativo, sobre a função de agir sobre o comportamento do leitor (instruções) e ao mesmo tempo informá-lo (e.g. advertências, contra indicações, efeitos colaterais). Esta classificação é associada à caracterização da superestrutura (VAN DIJK, 1992) da bula como institucional, pois o autor de sua macroestrutura (conteúdo) ao redigi-la, deve seguir as regras estabelecidas por uma instituição social, que neste caso é a ANVISA.

\subsection{A apresentação gráfica da bula de medicamento}

No intuito de discutir a concordância e a adequação da apresentação gráfica em bulas de medicamento, Van der Waarde (1999), estruturou um modelo para análise da apresentação gráfica deste tipo de documento. Segundo o autor, a concordância gráfica refere-se à relação entre o conteúdo da informação e sua apresentação visual, enquanto que a adequação da apresentação gráfica refere-se a o quanto a representação visual é apropriada nas bulas. $O$ modelo de Van der Waarde (1999), compreende três níveis de análise. O nível 1: componentes refere-se à verificação da existência dos seguintes componentes gráficos da bula de medicamento, enquanto documento instrucional/informativo: 


\section{Infodesıgn}

- Componentes Verbais: são todos os elementos que podem ser pronunciados (Figuras 8 e 9);

- Componentes Pictóricos: são todas as marcas que podem ser interpretadas como figura (Figuras 8 e 9);

- Componentes Esquemáticos: são combinados com outros tipos de componentes gráficos (verbal e pictórico), que geralmente são: marcadores, cores de fundo, linhas de sublinhamento, etc (Figuras 8 e 9);

- Componentes Composto: são uma composição de elementos gráficos que não podem ser muito separados, mas podem ser constituídos de qualquer combinação de componente verbal pictórico ou esquemático, por exemplo: gráficos, tabelas e diagramas (Figuras 6, 7 e 8).

Figura 6: Exemplo de componentes verbal, pictórico e esquemático na bula de medicamento

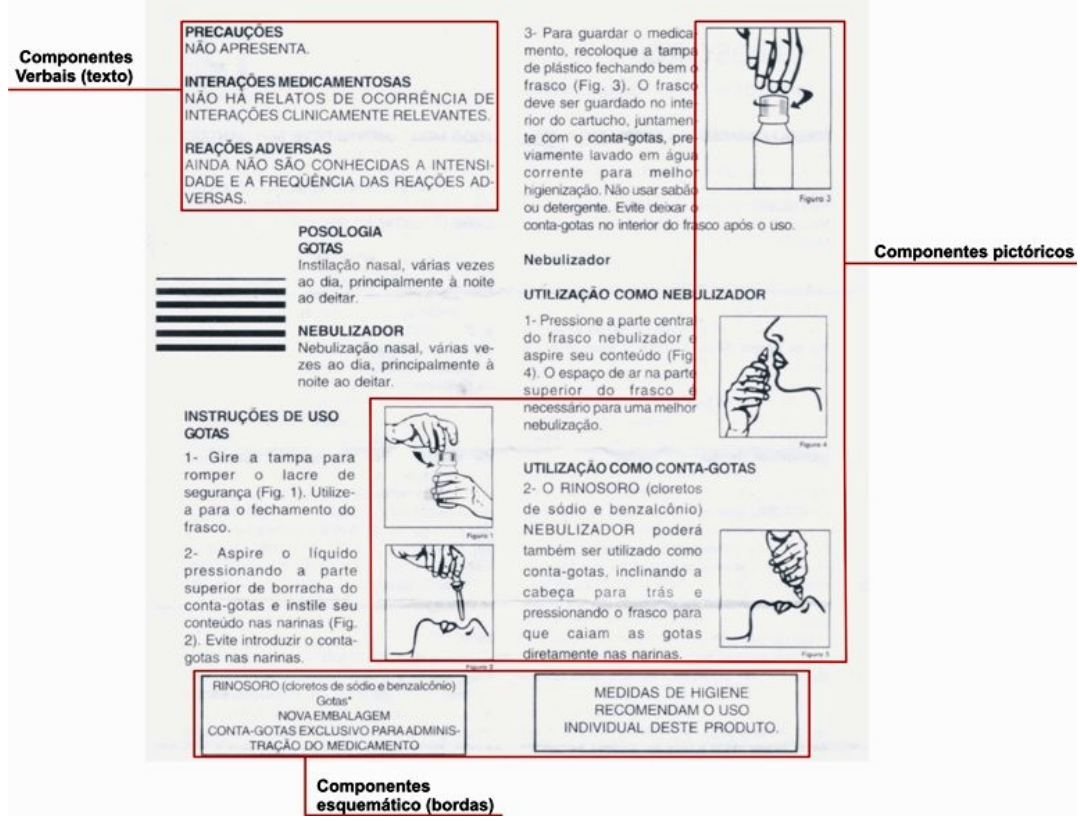

Figura 7: Exemplo de componentes verbal, pictórico, esquemático e composto na bula de medicamento

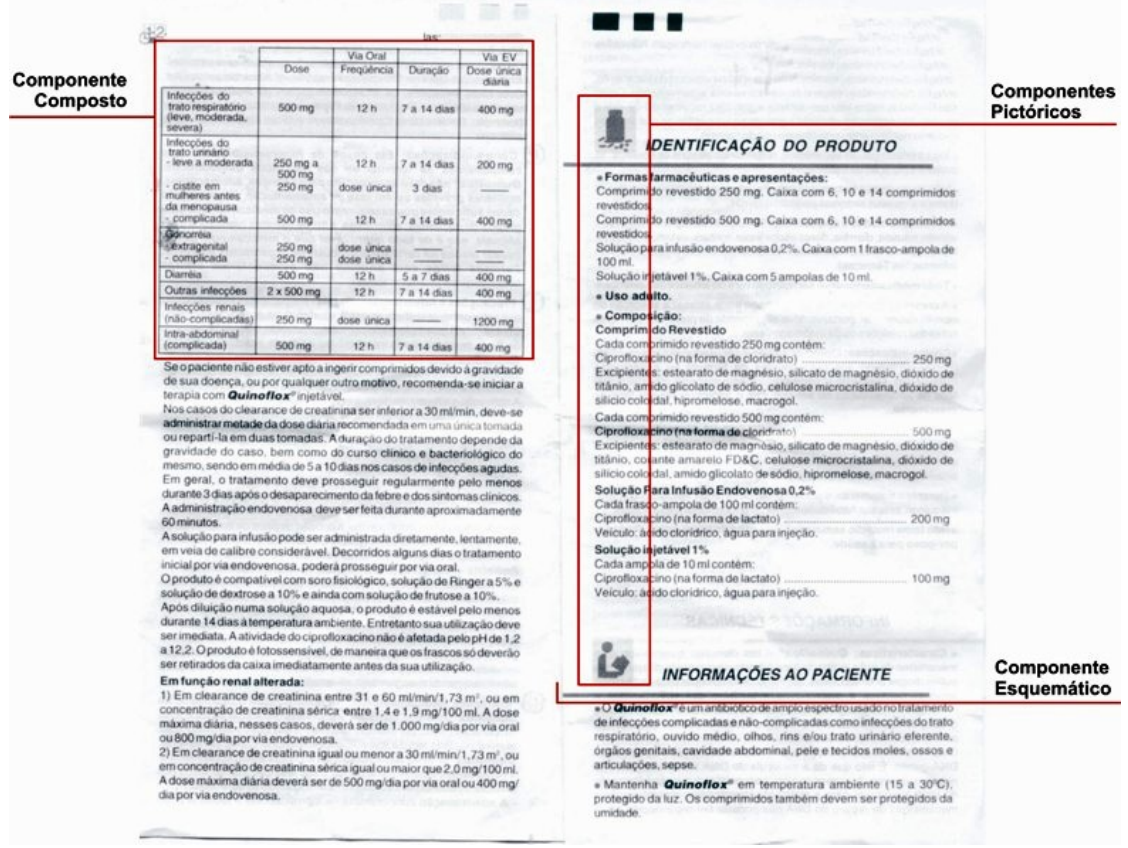


Figura 8: Exemplo de componente composto na bula de medicamento

\begin{tabular}{|c|c|c|c|c|c|}
\hline Tratamento & $\underset{\text { (mcg/ml) }}{\mathrm{C}_{\max }}$ & $T_{\max }(\mathrm{h})$ & $\begin{array}{c}\mathrm{AUC}_{\mathrm{0-1}} \\
\text { (mcg.h/ml) }\end{array}$ & $\begin{array}{c}\text { AUC }_{0 \cdot \text {.int }} \\
\text { (mcg.h/ml) }\end{array}$ & $\begin{array}{l}\text { Tempo Médio de } \\
\text { Residência (h) }\end{array}$ \\
\hline $\begin{array}{l}\text { Celen } \$ A F 750 \mathrm{mg} \\
\text { (alimentado) }\end{array}$ & $15,15 \pm 4,5$ & $2,83 \pm 0,69$ & $40.96 \pm 12,3$ & $52,64 \pm 11,8$ & $3,86 \pm 0,70$ \\
\hline $\begin{array}{l}\text { Cépsulas de } \\
\text { cefalexina } 500 \mathrm{mg} \\
\text { (alimentado) }\end{array}$ & $18,12 \pm 5,3$ & $1,69 \pm 0,50$ & $36,61 \pm 8,20$ & $38.32 \pm 8.4$ & $2,61 \pm 0,51$ \\
\hline
\end{tabular}

O nível 2: analisa as relações entre os componentes gráficos constatados, as quais são:

- Relação de Proximidade: refere-se à distância entre os componentes gráficos que são posicionados próximos um do outro, sugerem ter uma forte relação entre os elementos de informação;

- Relação de Similaridade: é uma indicação de parentesco funcional, componentes que parecem similares possuem um status hierárquico similar. Componentes gráficos que aparentam ser diferentes apresentam elementos de informação com um diferente status;

- Proeminência: as diferenças entre os componentes gráficos são uma indicação da importância no status hierárquico entre os elementos de informação, quanto maior o contraste entre componentes gráficos, maior a diferença no status da informação;

- Relação de Seqüencialidade: a seqüência dos componentes gráficos indica a sucessão dos elementos de informação.

E o nível 3 examina a apresentação gráfica global da bula, com relação à:

- Consistência: o consistente uso de componentes gráficos e relações entre componentes de todo o encarte pode tornar a estrutura da informação mais fácil de ser compreendida.

- Características físicas: seriam as características materiais do documento, no caso: qualidade de impressão e transparência do papel); e

- Estética: relacionada à apresentação gráfica geral em aspectos estéticos.

Em síntese, o modelo de Van der Waarde (1999), compreende três níveis de análise. O nível 1 refere-se à verificação da existência de componentes gráficos que compõe a bula de medicamento; o nível 2 analisa as relações entre os componentes gráficos identificados; e o nível 3 examina a apresentação gráfica global da bula.

\subsubsection{Hierarquia gráfica informacional}

O modelo de Van der Waarde (1999), além de analisar os diferentes tipos de componentes gráficos que compõe o conteúdo da bula, permite avaliar a hierarquia gráfica das informações, especialmente as textuais.

A hierarquia gráfica informacional refere-se a recursos gráficos utilizados na forma tipográfica do conteúdo textual que atribuem grau de importância à informação através da diferenciação e relação entre seus componentes, como por exemplo: negrito, caixa alta, caixa baixa, espaço, cor, etc. Estes recursos constituem um dos fatores gráficos mais relevantes na representação de informação textual, e no caso da bula são essenciais, considerando que seu conteúdo é constituído por diversos tipos de informações de status hierárquico distintos.

Twyman (1982) classifica e distingue esses recursos como características intrínsecas e extrínsecas da linguagem gráfica verbal. As intrínsecas são as características próprias dos caracteres, e seus aspectos particulares: itálico, negrito, tamanho e estilo. As extrínsecas são aquelas relacionadas à configuração dos caracteres: espaço (entre palavras, entrelinhas, parágrafos) e cor. 


\section{Infodesıgn}

As características intrínsecas e extrínsecas (TWYMAN, 1982) definem as relações de hierarquia gráfica informacional entre os componentes de um texto. Essas relações são caracterizadas por Van der Waarde (1999) como proeminência e similaridade (Figura 9), as quais, de acordo com estudos realizados utilizando este modelo como ferramenta de análise (FUJITA \& SPINILLO, 2006; SPINILLO et al, 2007), constituem as maiores deficiências na apresentação gráfica do conteúdo textual em bulas de medicamento.

\begin{tabular}{|c|c|c|}
\hline & $\begin{array}{l}\text { TODO MEDICAMENTO DEVE SER MANTIDO FORA DO ALCANCE DAS } \\
\text { CRIANÇAS. }\end{array}$ & Advertência \\
\hline & $\begin{array}{l}\text { Este produto está contra-indicado em pacientes com hipersensibilidade } \\
\text { às cefalosporinas e aos componentes de sua fórmula.Informe ao seu } \\
\text { médico sobre qualquer medicamento que esteja usando, antes do } \\
\text { início, OU durante o tratamento. } \\
\text { NĀO TOME MEDICAMENTO SEM O CONHECIMENTO DO SEU } \\
\text { MÉDICO. PODE SER PERIGOSO PARA A SAÚDE. }\end{array}$ & Advertência \\
\hline Titulo & INFORMAÇŌES TÉCNICAS & \\
\hline \multirow[t]{2}{*}{ Subtítulo } & CARACTERISTICAS QUIMICAS E FARMACOLÓGICAS & \\
\hline & $\begin{array}{l}\text { A cefalexina é um antibiótico cefalosporinico semi-sintético para } \\
\text { administraçấo oral. Quimicamente é o ácido } 7-(\mathrm{D} \text {-amino- } \\
\text { fenilacetamido)-3-metil-3-cefem-4-carboxilico monoidratado. A } \\
\text { fórmula molecular para cefalexina é } \mathrm{C}_{16} \mathrm{H}_{17} \mathrm{~N}_{3} \mathrm{O}_{4} \mathrm{~S} \text {. } \mathrm{H}_{2} \mathrm{O} \text { e seu peso } \\
\text { molecular é de } 365,4 \text {. }\end{array}$ & \\
\hline
\end{tabular}

\section{Conclusão}

Este artigo abordou o conteúdo informacional da bula de medicamento na perspectiva do design da informação. De acordo com as considerações apresentadas por Walker (2001) e Ferreira e Dias (2005) sobre a existência de uma relação entre a organização visual do conteúdo informacional de um documento e a sua intenção de uso, é necessário considerar, neste caso, o leitor da bula, pois parte da leitura de um texto é determinada pelos seus conhecimentos e experiências. Neste sentido, foram apresentadas considerações sobre o conteúdo informacional da bula, focando sobre a estrutura e apresentação gráfica (de acordo com as normas da ANVISA) em relação a seu autor (fabricante) e leitor (paciente/usuário).

Sobre a estrutura textual, apresentaram-se as funções textuais da bula denominadas por Marshall (1984) e sua classificação superestrutural, de acordo com Van Dijk (1992). De acordo com o modelo de Marshall (1984), o texto da bula de medicamento foi determinado como diretivo informativo, sobre a função agir sobre o comportamento do leitor (instruções) e ao mesmo tempo informá-lo (e.g. advertências, contra indicações, efeitos colaterais). Esta classificação é associada à caracterização da superestrutura (VAN DIJK, 1992) da bula como institucional, pois o autor de sua macroestrutura (conteúdo) ao redigi-la, deve seguir as regras estabelecidas por uma instituição social, que neste caso é a ANVISA.

Em relação à composição gráfica, o modelo analítico estruturado por Van der Waarde (1999) analisa a bula de medicamento ao nível de sua forma de apresentação gráfica, possibilitando identificar principalmente as relações entre os componentes verbais, sendo possível constatar problemas de legibilidade e hierarquia da apresentação gráfica do conteúdo textual das bulas. Quanto à hierarquia da apresentação gráfica, Twyman (1982) denomina como características intrínsecas e extrínsecas (TWYMAN, 1982), que definem as relações de hierarquia gráfica informacional entre os componentes de um texto. 


\section{Agradecimentos}

Agradeço à CAPES pelo apoio financeiro, e à minha orientadora, Dra. Carla Galvão Spinillo por todo o apoio, orientação e dedicação.

\section{Referências}

BRASIL. Ministério da Saúde. Resolução RDC № 140, de 29 de maio de 2003. Disponível em: http://e-legis.anvisa.gov.br/leisref/public/showAct.php?id=6311. Acesso em: 12 de novembro de 2008.

DICKINSON, D.; RAYNOR, T. D. K.; KENNEDY, J. G.; BONACCORSO, S.; STURCHIO, J et al. 2003. What information do patients need about medicines? BMJ, Education and Debate. Vol. 327, pp. 861-864.

FERREIRA, Sandra Patrícia Ataíde; DIAS, Maria da Graça B. B. 2005. Reader and reading: considerations about text types and meaning construction. Psicol. Reflex. Crit., Porto Alegre, v. 18, n. 3.

GIASSON, J. A compreensão na leitura. 1993. Lisboa: Asa, 317p.

MARSHALL, N. Discourse analysis as a guide for informal assessment of comprehension. 1984. In: FLOOD, J. (Ed.). Promoting Reading Comprehension. Newark, Delaware, International Reading Association, pp.79-97.

SLESS, David. TYERS, Alex. Case history \# 5 | Panadol 24 Pack: new instructions for consumers. CRIA, 2004. Disponível em: http://www.communication.org.au/cria_publications/publication_id_89_1290110197.html. Acesso em 20 de outubro de 2006.

SPINILLO, C. G. Instruções visuais: algumas considerações e diretrizes para seqüências pictóricas de procedimentos. 1999. Estudos em Design. volume 9, n³ 3, Rio de Janeiro.

Are visual instructions successful messages? Some considerations in the analysis of procedural pictorial sequences. 2002. In: Selected Readings of the International Visual Literacy Association, p. 1-10.

; PADOVANI, S.; MIRANDA, F.; FUJITA, P. T. L. et al. 2007. Instruções visuais em bulas de medicamentos no Brasil: um estudo analítico sobre a representação pictórica da informação. In: $3^{\circ}$ Congresso Internacional de Design da Informação, 2007, Curitiba. Anais. Curitiba: SBDI, 1CD-ROM. ISBN: 978-85-89879-04-0.

TWYMAN, M. The graphic presentation of language. Information Design Journal. 1982. Vol. 3 , n.1, ISSN: 0142-5471.

VAN DER WAARDE, Karel. The graphic presentation of patient package inserts. 1999. In: ZWAGA, Harm J. G. BOERSEMA, Theo. HOONHOUT, Henriëtte C. M. (Ed) Visual information for everyday use: Design and research perspectives. London, Taylor \& Francis, p. 75-81.

VAN DER WAARDE, K. Visual information about medicines. Providing patients with relevant information. 2004. SPINILLO, Carla G.; COUTINHO, Solange G. (Eds). Selected Readings of the Information Design International Conference 2003. Recife, SBDI | Sociedade Brasileira de Design da Informação, p. 81-89.

VAN DER WAARDE, K. Visual information about medicines for patients. Jorge Frascara. (Eds). Designing Effective Communications: Creating contexts for clarity and meaning. New York: Allworth Press, 2006. p. 38-50.

VAN DIJK, T. A. Discourse analysis: its development and application to the structure of news. 1983. Journal of Documentation, v.33, n.2, p. 20-23.

VAN DIJK, T. A. La ciencia del texto: Un enfoque interdisciplinario. 1992. Barcelona: Ediciones Paidos.

WALKER, S. Typography and Languange in Everyday Life: Prescriptions and Practice. 2001. Essex: Pearson Education Limited. 


\section{Infodesıgn}

WRIGHT, P. Comprehension of printed instructions: examples from health materials. 1999. In D. Wagner, R. Venezky, \& B. Street (Eds.) Literacy: an international handbook. Boulder, CO: Westview Press, p. 192-198

WRIGHT, P. Printed Instructions: Can research make a difference? 1999. In: ZWAGA, Harm J. G. BOERSEMA, Theo. HOONHOUT, Henriëtte C. M. (Ed) Visual information for everyday use: Design and research perspectives. London, Taylor \& Francis, p. 45-66.

\section{Sobre a autora}

Patricia Lopes Fujita é mestranda do Programa de Pós-Graduação em Design - UFPR

<patricia.fujita@gmail.com>

Carla Galvão Spinillo é bolsista produtividade do CNPq, docente da UFPR-Universidade Federal do Parana, e colaboradora docente PPGDesign da ESDI-UERJ, vice-presidente da International Visual Literacy Association, EUA e co-editora da InfoDesign - Revista Brasileira de Design da Informação. Foi presidente da Sociedade Brasileira de Design da Informação nas gestões 20032005 e 2005-2007. Tem expertise em Design da Informação, atuando principalmente nos seguintes temas: design instrucional e linguagem gráfica.

<cgspin@terra.com.br> 